\title{
PREPARATION AND PROPERTIES OF BIONANOCOMPOSITE FILMS REINFORCED WITH NANOCELLULOSE ISOLATED FROM MOROCCAN ALFA FIBRES
}

\author{
Benyoussif Youssef ${ }^{\mathrm{a}, \mathrm{d} *}$, Aboulhrouz Soumiab, El Achaby Mounirc, Cherkaoui Omara, \\ Lallam Abdelaziz ${ }^{\mathrm{d}}$, El Bouchti Mehdia ${ }^{\mathrm{a}}$ Zahouily Mohamed ${ }^{\mathrm{b}, \mathrm{c} * *}$
}

\author{
'Laboratoire de recherche sur les matériaux textiles, Ecole supérieure des industries de textile et de l'habillement, 20220 Casablanca, Morocco \\ bLaboratoire de Matériaux, Catalyse et Valorisation des Ressources Naturelles, URAC 24, Faculté des Sciences et Techniques, \\ Université Hassan II-Casablanca B.P. 146, 20650, Morocco \\ "Moroccan Foundation for Advanced Science Innovation and Research (MAScIR), Rabat Design, \\ Rue Mohamed El Jazouli, Madinat El Irfane 10100-Rabat, Morocco \\ ¿Laboratoire de Physique et Mécanique Textiles, Ecole Nationale Supérieure d'Ingénieurs Sud Alsace, 68093 Mulhouse, France \\ E-mail: *benyoussif@esith.ac.ma; **mzahouily@gmail.com
}

\begin{abstract}
:
Nanocellulose (NC) were extracted from the Moroccan Alfa plant (Stipa tenacissima L.) and characterised. These Alfa cellulosic nanoparticles were used as reinforcing phase to prepare bionanocomposite films using carboxymethyl cellulose as matrix. These films were obtained by the casting/evaporation method. The crystallinity of NC was analysed by X-ray diffraction, the dimension of NC by atomic force microscopy, molecular interactions due to incorporation of NC in carboxymethyl cellulose (CMC) matrix were supported by Fourier transforms infrared (FTIR) spectroscopy. The properties of the ensuing bionanocomposite films were investigated using tensile tests, water vapour permeability (WVP) study and thermogravimetric analysis. With the progress of purification treatment of cellulose, the crystallinity is improved compared to the untreated fibres; this can be explained by the disappearance of the amorphous areas in cellulose chain of the plant. Consequently, the tensile modulus and tensile strength of CMC film increased by 60 and 47\%, respectively, in the bionanocomposite films with 10 wt\% of NC, and decrease by $8.6 \%$ for WVP with the same content of NC. The NC obtained from the Moroccan Alfa fibres can be used as a reinforcing agent for the preparation of bionanocomposites, and they have a high potential for the development of completely biodegradable food packaging materials.
\end{abstract}

\section{Keywords:}

Alfa fibres, nanocellulose, carboxymethyl cellulose, bionanocomposite film, characterisation.

\section{Introduction}

In recent years, more attention has been paid to natural polymers for sustainable development and environmental preservation [1-3]. There has been spectacular development and rapidly growing interest in renewable biopolymers derived, especially from natural resources for a wide range of applications (biodegradable packaging materials, automotive industries, agriculture, pharmaceuticals...) [4-7].

In this context, Alfa grasses have been used in various composite applications $[8,9]$. The main components of these fibres are cellulose, hemicellulose and lignin. These fibres are characterised by their interesting physical and mechanical properties that favour its exploitation to produce biodegradable composites [8-9]. In North Africa, Alfa is a name of the plant Stipa tenacissima L. Species belongs to the grass family typically Mediterranean localised, especially in the western part of the Mediterranean region. It covers a large area estimated to about $3,186,000$ ha in Morocco, $4,000,000$ ha in Algeria, 400,000 ha in Tunisia and 350,000 ha in Libya [10-12].

Cellulose is the most abundant natural polymer in the biosphere. It has been extensively studied in both theory and experimentation. Carboxymethyl cellulose (CMC) is a derivative of cellulose and can be produced from annual plant pulps, cotton cellulose and wood. It is produced by introducing - $\mathrm{CH}_{2} \mathrm{COOH}$ groups into cellulose molecular chain. According to unique physicochemical properties such as non-toxic, viscosity, transparency, hydrophilicity and biodegradability [13, 14], CMC can be employed for several applications such as medicine constituents, viscosity controllers, paper industry, detergents, food and textile printing among others [15-17].

Nanocellulose (NC) is also a cellulose derivative composed of a nanosized fibre network, which determines the product properties and its functionality. It has generated much attention and interest during these few last decades because of their value-added applications in science and technology, for example, (1) in pharmaceutical formulations, as a potential direct compression excipient, especially in the design and development of tablets of poorly compressible and soluble drug [18-20]; (2) in food industry, as stabiliser, emulsifier, thickener and gelling agents in several dairy [21, 22]; (3) in nanocomposite materials with improved mechanical properties and good tensile strength [23]. NC fibres' quality depends on the cellulose raw materials, its pretreatment, and more crucially on the disintegrating process itself. Several processes of 
extraction have been described from various cellulose sources such as mechanical treatments [24], chemical treatments [25], and biological treatments [26]. However, chemical methods, for example, acid hydrolysis, are the conventional method of choice for manufacturing NC having a great crystallinity [25]. $\mathrm{NC}$ are very interesting nanomaterials for production of cheap, lightweight and very strong nanocomposites (Young's modulus of the cellulose crystal is as high as $134 \mathrm{GPa}$ ). A considerable amount of research has been done on the isolation of these nanofibres from plants for use as fillers in the next generation of biodegradable materials. To improve properties of $\mathrm{CMC}$, different nanoparticles have been incorporated into CMC matrix, such as graphene oxide [27], silver nanoparticles [28, 29], ferrite nanoparticles [30], cellulose nanocrystal [31], hydroxyapatite [32], calcium carbonate [33], ZnS [34] and copper complexes [35].

In this study, we evaluate the effect of incorporation of NC on the mechanical, thermal and water vapour barrier properties of $\mathrm{CMC}$ bionanocomposite films. The NC/CMC bionanocomposite films have been prepared by casting NC/CMC aqueous solution. The microstructure, mechanical, thermal and water vapour permeability of $\mathrm{NC/CMC}$ bionanocomposite films were examined as function of $\mathrm{NC}$ content by Fourier transform infrared (FTIR), thermogravimetric analysis (TGA), water vapour permeability (WVP) and mechanical tests. The NC content in the bionanocomposite films ranged from 0 to 10 wt $\%$. The crystallinity of NC was analysed by X-ray diffraction (XRD) and atomic force microscopy (AFM).

\section{Experimental}

\subsection{Raw material}

Alfa fibres were collected from the Oujda area, in Morocco, during the period of April-May 2012. The CMC, with a nominal molecular weight of $700.000 \mathrm{~g} . \mathrm{mol}^{-1}$, used in the present work was supplied by Sigma-Aldrich. Preliminary tests showed that the preparation of $\mathrm{CMC}$ solutions requires a minimum time to fully dissolve the CMC powder. This time depends on the polymer concentration and the temperature. Consequently, aqueous solutions of CMC were prepared by dissolving the appropriate amount of CMC in distilled water at room temperature. All commercial reagents were purchased from Aldrich Chemical Co.

\subsection{Pulping and bleaching}

The Alfa plant was milled with a laboratory milling device (POLYMIX_PX-MFC $90 \mathrm{D}$ ) to obtain fine particulate substance. The Alfa fibres were extracted in a 4 wt\% aqueous $\mathrm{NaOH}$ solution at room temperature under mechanical stirring during $2 \mathrm{~h}$. This treatment was done two times to purify cellulose by removing other constituents present in the fibres. After each treatment, fibres were filtered and washed with distilled water until the alkali was completely eliminated. To bleach the fibres, the residue was treated with solution of equal parts of acetate buffer, aqueous chlorite (1.7 wt\% in water), and distilled water at $80^{\circ} \mathrm{C}$ under mechanical stirring during $2 \mathrm{~h}$ and was repeated two times. After this treatment, the cellulose pulp was washed with distilled water until $\mathrm{pH}$ of 7 was reached. At last, the residue obtained was dried for $24 \mathrm{~h}$ at $60^{\circ} \mathrm{C}$.

\subsection{Nanocellulose preparation}

The dry cellulose Alfa fibre was hydrolysed with preheated $\mathrm{H} 2 \mathrm{SO} 4(64 \mathrm{wt} \%)$ with fibre to solution ratio of $1: 12(\mathrm{~g} / \mathrm{ml})$ for $30 \mathrm{~min}$ at $45^{\circ} \mathrm{C}$ under strong agitation. The reaction was quenched by adding an excess of distilled water to the reaction mixture and the resulting mixture was then cooled to the room temperature. Then, the suspension was centrifuged at 9000 $\mathrm{rpm}$ at $20^{\circ} \mathrm{C}$ for $15 \mathrm{~min}$ in a bench-top centrifuge (Hettich Universal 320) repeatedly and the supernatant was discarded until it became turbid. Subsequently, the fractions were washed with bi-distilled water by centrifugation. Under this condition, the $\mathrm{pH}$ of the suspension was above 5 . Then the suspension was subjected to dialysis with bi-distilled water until neutrality was attained. After this, the NC of the Alfa fibre obtained after freeze drying was snow white in appearance.

\subsection{Preparation of films}

The NC/CMC films with a NC content of 3, 5 and $10 \%(w / w)$, respectively, were prepared by solution casting from water. The $\mathrm{CMC}$ was first dissolved in water at a concentration of $1 \mathrm{wt} \%$ by stirring at room temperature for $8 \mathrm{~h}$. NC/water dispersions of a concentration of $1 \mathrm{mg} / \mathrm{ml}$ were prepared by mixing the components in the appropriate ratio and sonicated at $40 \%$ amplitude (BRANSON Analog Sonicator, 200W S-250 CE). Aliquots of the NC dispersions and $\mathrm{CMC} /$ water solution were combined, stirred for $15 \mathrm{~min}$, and cast into plastic dishes. The water was evaporated at ambient temperature over a period of at least 3 days and the obtained films were dried for $4 \mathrm{~h}$ at $40^{\circ} \mathrm{C}$ for evaporating the residual water. Neat CMC film was also prepared according to the processing method mentioned above, without the addition of the NC for properties comparison.

\subsection{Characterisation}

\subsubsection{FTIR spectroscopy}

FTIR spectra of samples were measured on a Nicolet iS10 spectrometer. The spectra were recorded in transmittance band mode in the range of $4000-600 \mathrm{~cm}^{-1}$. Spectra were achieved from 32 accumulated scans at $4 \mathrm{~cm}^{-1}$ were co-added in order to achieve an acceptable signal-to-noise ratio.

\subsubsection{XRD analysis}

XRD patterns of the samples were obtained at room temperature on a Bruker AXS D-8 diffractometer using Cu-Ka radiation in Bragg-Brentano geometry $(\theta-2 \theta)$. The diffraction patterns were obtained at diffraction angles between 5 and $50^{\circ}$ with a scanning rate $0.02 \% \mathrm{~min}$ at room temperature. The crystallinity index $(\mathrm{Crl} \%)$ of different cellulose samples was determined following the method of Segal et al. [36] (Eq. 1).

$$
\mathrm{Cr} I \%=\left[\frac{\mathrm{I}_{200}-\mathrm{I}_{\mathrm{am}}}{\mathrm{I}_{200}}\right]=100
$$


Where $\mathrm{I}_{200}$ and $\mathrm{I}_{\mathrm{am}}$ were the intensity of the 200 peak (at $2 \mathrm{~d}=$ $22^{\circ}$ ) and of the peak at $2 q=18^{\circ}$, respectively. The $d$-spacings were calculated using the Bragg's equation.

\subsubsection{Atomic force microscopy}

AFM measurement was carried out using a Veeco Dimension ICON. The samples used for AFM characterisations were deposited on mica sheets. [37]

\subsubsection{Thermogravimetric analysis}

TGA and derivative thermograms (DTGA) were conducted under nitrogen in Versa Therm apparatus (Thermofisher) with a $20^{\circ} \mathrm{C} / \mathrm{min}$ ramp between 25 and $1000^{\circ} \mathrm{C}$.

\subsubsection{Water vapour permeability}

WVP test of films was conducted using a method described by Vargas-Torres al. [37]. Prepared bionanocomposite films were hermetically sealed in a permeation cell $(3.0 \times 6.5 \times 2.0 \mathrm{~cm})$ that stored at $25^{\circ} \mathrm{C}$ in desiccators to maintain a $75 \% \mathrm{RH}$ gradient across the film, silica gel $(0 \% \mathrm{RH})$ was placed inside the cell, and a sodium chloride $(\mathrm{NaCl})$ saturated solution $(75 \%$ $\mathrm{RH}$ ) was used in the desiccators. Water vapour transport was determined from the weight gained on the permeation cell. The equilibrium conditions were reached after about 2 hours. Six weight measurements were taken over $6 \mathrm{~h}$. Changes in the weight of the cell were weighed using a four-digit balance and plotted as a function of time. At least three samples of each type of film were tested and WVP was calculated [38]. After the permeation tests, the film thickness and WVP ( $g /$ $\mathrm{Pa} / \mathrm{s} / \mathrm{m}$ ) were measured.

\subsubsection{Tensile properties}

Tensile tests were performed using a H50KS Hounsfield. The tensile specimens were cut in rectangular shapes with dimensions of $40 \mathrm{~mm}$ in length and $10 \mathrm{~mm}$ in width. The gauge length was fixed at $20 \mathrm{~mm}$ and the speed of the moving clamp was $10 \mathrm{~mm} / \mathrm{min}$. All tests were carried out on a minimum of five samples and the reported results are average values.

\section{Results and discussion}

The composition of Alfa grass is $40.5 \%$ of pure cellulose, $22.8 \%$ of hemicellulose, $22.5 \%$ of lignin, $2.3 \%$ of hot water extractives, $10.2 \%$ of organic solvents extractives and $1.7 \%$ of ash. The ash content was analysed according to the standard method ASTM D 110284 (Reapproved 1990), hot water extracts were determined using the standard method ASTM1110 56 (Reapproved 1977), organic solvents extracts were analysed using the standard method ASTM D 1107 (Reapproved 1972) modified by replacing benzene with toluene, the hemicellulose content was determined according to ASTM D 110456 (Reapproved 1978), the lignin content was analysed using ASTM D 110656 (Reapproved 1977) and, finally, the determination of a-cellulose was carried out according to ASTM D 110360 (Reapproved 1978).
The morphological and chemical characteristics of NC were analysed by AFM, FTIR spectroscopy, XRD and TGA. FTIR spectra of Alfa fibres (Alfa-F), Alfa-cellulose (Alfa-C) and $\mathrm{NC}$ samples are given in Figure 1. The dominant peaks at approximately $3300 \mathrm{~cm}^{-1}$ and $2900 \mathrm{~cm}^{-1}$ were attributed to $\mathrm{OH}-$ stretching and $\mathrm{CH}$-stretching of the cellulose present in the all samples. The band observed in the spectra of both samples at $1034 \mathrm{~cm}^{-1}$ is due to the $\mathrm{C}-\mathrm{O}-\mathrm{C}$ stretching vibration and the peak at $895 \mathrm{~cm}^{-1}$ indicates $\mathrm{C}-\mathrm{H}$ rocking vibration of cellulose present in the Alfa-C and NC. Other peaks, such as the peak at $1512 \mathrm{~cm}^{-1}$ is attributed to the $\mathrm{C}=\mathrm{C}$ bond elongation of the lignin aromatic ring, and symmetric $\mathrm{CH}_{2}$ bending vibration [39]. The band at $1735 \mathrm{~cm}^{-1}$ is attributed to the acetyl group of hemicellulose uronic ester or the carboxylic ester group of the ferulic ring and $p$-coumaric acid of lignin and/or hemicellulose $[40,41]$. This result indicates that the extraction of lignin and hemicellulose has been effective. Interestingly, no difference was found between the spectrum of NC and Alfa-C. This result suggests that the acid hydrolysis of Alfa-C did not affect the chemical structure of the cellulose fragments [42]. During the hydrolysis process, the esterification reaction occurred, giving the appearance of a small peak at $1206 \mathrm{~cm}^{-1}$ in the NC spectrum assigned to the $\mathrm{S}=\mathrm{O}$ vibration. This result is reported in the literature $[43,44]$.

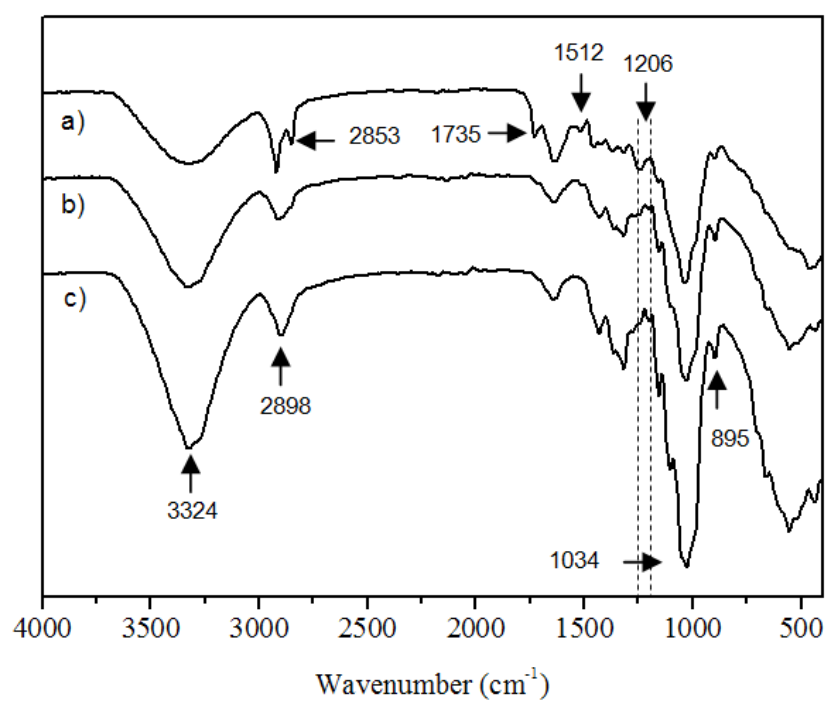

Figure 1: FTIR spectra of a) Alfa-F, b) Alfa-C and c) NC

The XRD patterns of Alfa-F, Alfa-C as well as NC are shown in Figure 2. Both diffractograms showed at $2 q$ of $22.6^{\circ}$ and a shoulder in the $2 q$ range $10-18^{\circ}$, which represent typical cellulose structure [45]. However, the intensity of the peaks of $\mathrm{NC}$ was significantly higher than that of the Alfa-F and Alfa-C, respectively [46-48]. On the other hand, the higher diffraction peak of $2 q$ of $22.6^{\circ}$ of NC indicated that the crystallinity index of $\mathrm{NC}$ is greater than that of the Alfa F and Alfa-C (Table 1).

The crystallinity index of three samples of Alfa-F, Alfa-C and NC was $46 \%, 64 \%$ and $71 \%$, respectively, using Segal's empirical method. The crystallinity index significantly increased because the removal of amorphous components from Alfa- $F$ to Alfa- $C$ and amorphous region from Alfa-C to NC by the acid hydrolysis [49]. It was indicated that the intermolecular hydrogen bonds of 


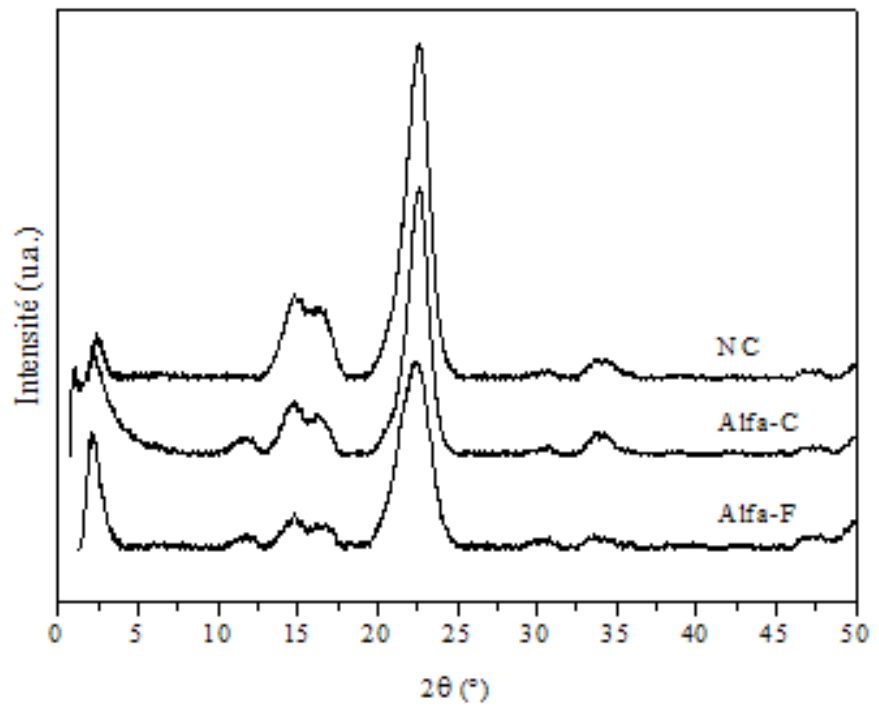

Figure 2: XRD patterns of cellulose samples studied

cellulose were broken, causing the collapse of crystal structure during the whole process [50].

To get a more accurate idea about the dimension scale of the as-extracted of NC, AFM observations were carried out on
Table 1: Results obtained from the X-ray diffraction analysis for the cellulose samples studied

\begin{tabular}{|c|c|c|c|c|}
\hline \multirow{2}{*}{ Sample } & \multicolumn{3}{|c|}{ d-spacings (nm)a } & \multirow{2}{*}{$\begin{array}{c}\text { Crl } \\
(\%)\end{array}$} \\
\cline { 2 - 4 } & & 110 & $\mathbf{2 0 0}$ & $(\mathbf{6})$ \\
\hline Alfa-F & 0.599 & 0.546 & 0.397 & 46 \\
\hline Alfa-C & 0.597 & 0.546 & 0.393 & 64 \\
\hline NC & 0.599 & 0.546 & 0.394 & 71 \\
\hline
\end{tabular}

ad-spacings of typical three equatorial peaks of cellulose samples (using XDR analysis); ${ }^{\text {b}}$ Crystallinity index using XRD analysis

samples obtained by applying one drop of an aqueous NC dispersion on freshly cleaved mica sheets. It is well known that the AFM observation is an appropriate method for the analysis of the exact dimensions of NC [51-53]. Herein, AFM images of $\mathrm{NC}$ are shown in Figure 3. Excess water was removed by drying the sample in an oven at $50^{\circ} \mathrm{C}$ for $1 \mathrm{~h}$. The dimensions and aspect ratio (length:diameter) of $\mathrm{NC}$ made under the optimised hydrolysis conditions $30 \mathrm{~min}$ at $45^{\circ} \mathrm{C}$ with a $\mathrm{H}_{2} \mathrm{SO}_{4}$ concentration of $64 \mathrm{wt} \%$ were determined by analysis of the AFM images (Figure 3), resulting in an average diameter of $8 \pm$ $2 \mathrm{~nm}$, an average length of $246 \pm 64 \mathrm{~nm}$, as calculated from the high profiles shown in Figure 3 taken in two different positions.
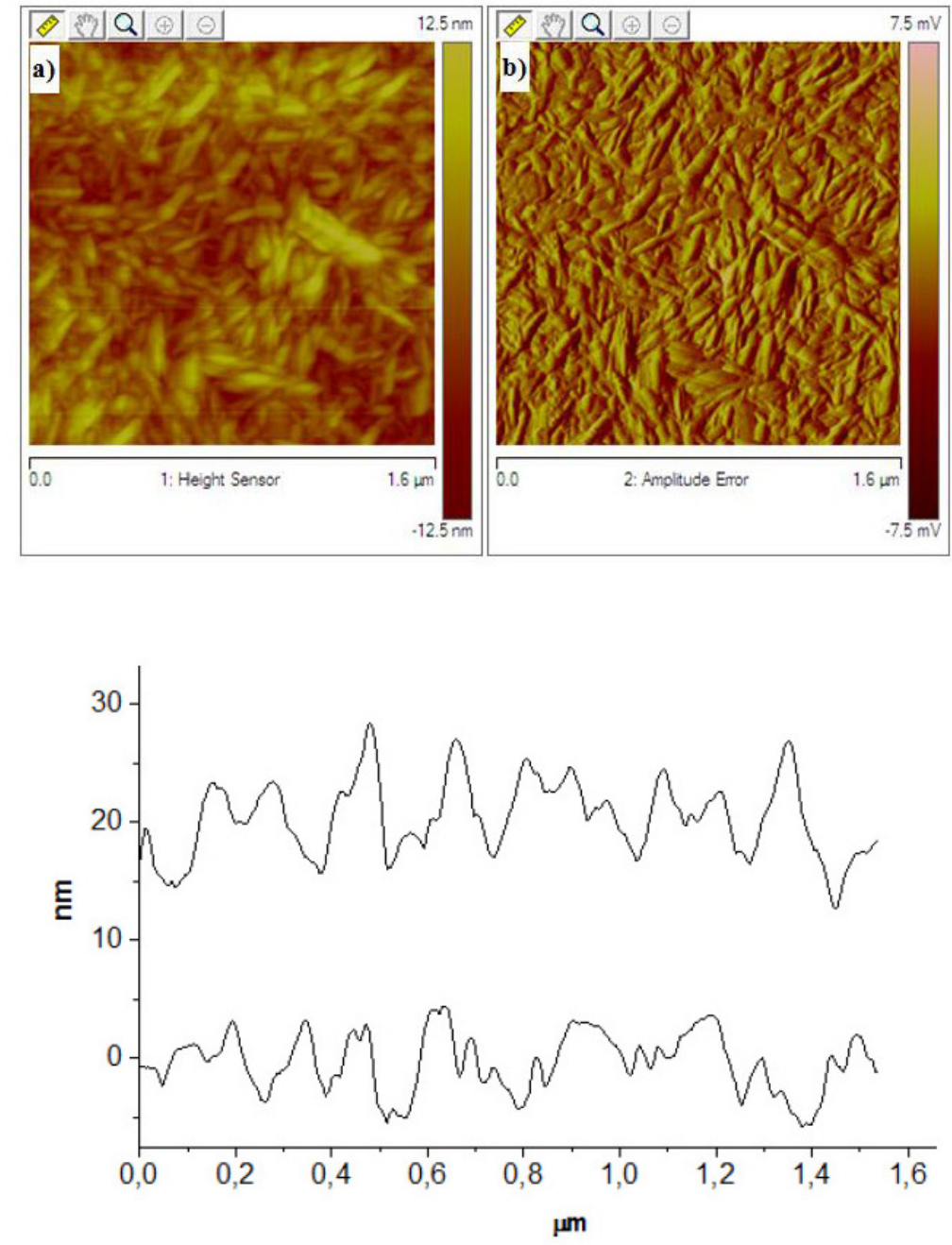

Figure 3: The AFM images show an area of $1.6 \times 1.6 \mathrm{~mm}$. AFM images of NC height (a) and amplitude (b) tapping mode 
The average aspect ratio of as-extracted NC is calculated at $31 \pm 0.7 \mathrm{~nm}$.

The thermal stability is important for future applications of cellulose fibres in development of entirely biodegradable packaging materials. The TGA curves for Alfa-F, Alfa-C and NC samples are shown in Figure 4. Table 2 shows the result obtained from these curves. The drying stage for all samples occurs at a temperature range $70-160^{\circ} \mathrm{C}$ approximately, which

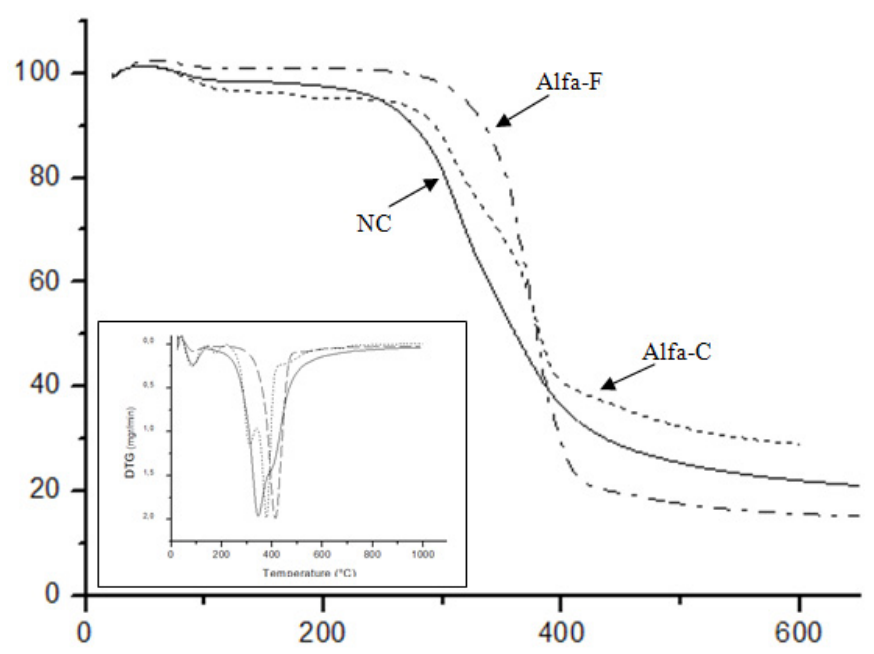

Figure 4: TGA/DTGA pyrolysis curves of cellulose samples is due to the evaporation of water. As can be seen, the onset decomposition temperature was $267^{\circ} \mathrm{C}$ for Alfa-F, $291^{\circ} \mathrm{C}$ for Alfa-C and $239^{\circ} \mathrm{C}$ for NC, respectively, (Figure 3). For Alfa-F, a weight loss was observed due to degradation processes of lignin, hemicellulose and cellulose, such as dehydration, decarboxylation, depolymerisation and decomposition of glycosyl units followed by the formation of a charred residue. The NC exhibited the lowest thermal stability due to the introduction of sulphated groups to the nanocrystals during the $\mathrm{H} 2 \mathrm{SO} 4$ hydrolysis of the Alfa F $[54,55]$.

The NC/CMC bionanocomposite films with a NC content of 3,5 , and $10 \%(w / w)$, were prepared by solution casting from water. Generally, all the dried bionanocomposite films were transparent, as shown in Figure 5.

Table 2: Results of thermogravimetric analysis of cellulose samples studied

\begin{tabular}{|c|c|c|c|}
\hline \multirow{2}{*}{ Sample } & \multicolumn{3}{|c|}{ TGA analysis } \\
\hline & Onset $\left({ }^{\circ} \mathrm{C}\right)^{\mathrm{a}}$ & Peak $\left({ }^{\circ} \mathrm{C}\right)^{b}$ & Wt $(\%)^{c}$ \\
\hline Alfa-F & 267 & 378 & 73 \\
\hline Alfa-C & 291 & 375 & 85 \\
\hline $\mathrm{NC}$ & 239 & 315 & 80 \\
\hline
\end{tabular}

aOnset decomposition temperature using TGA; 'Peak temperature of DTGA; ' Residual weight at $600^{\circ} \mathrm{C}$.
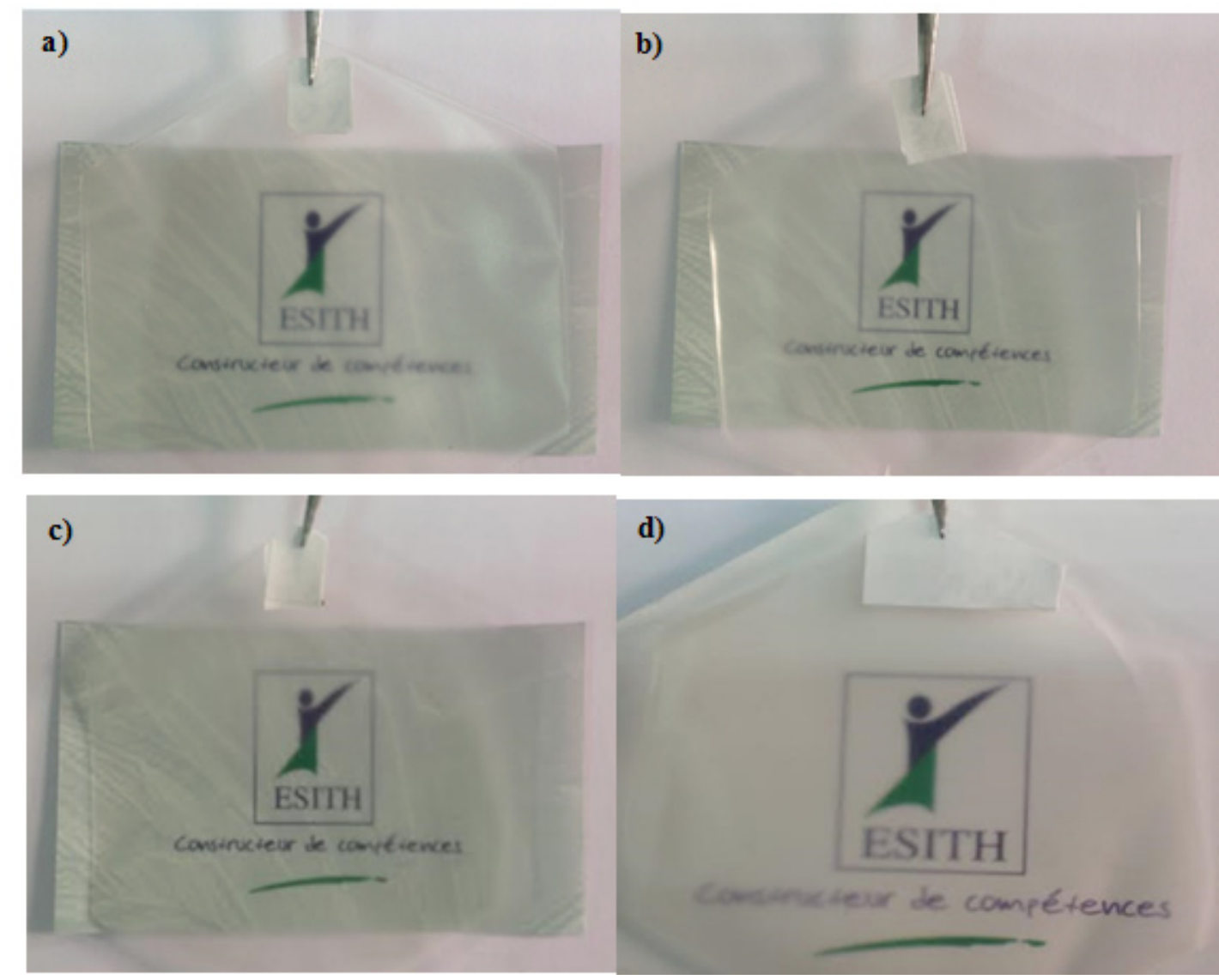

Figure 5: Pictures of films of a) neat $\mathrm{CMC}$ and $\mathrm{CN} / \mathrm{CMC}$ nanocomposite films b) NC $3 \%$, c) NC $5 \%$ and d) NC $10 \%$ 
Figure 6 shows the FTIR spectra of $\mathrm{CMC} / \mathrm{NC}$ nanocomposites films containing 3,5 , and $10 \% \mathrm{NC}$, respectively. Hence, this analysis attempted to characterise the incorporation of NC into the CMC films matrix and distinguish the IR bands and vibrations shifts related to NC interactions. Few differences can be observed in the whole IR region after addition of NC into film matrix because NC was a similar chemical structure to that $\mathrm{CMC}$. The presence of hydrogen-bound $\mathrm{O}-\mathrm{H}$ sulphate groups caused a low shift of absorption to lower frequencies with the disappearance of peak at $1643 \mathrm{~cm}^{-1}$ present in NC. The absorption peaks of all films (CMC and CN/CMC films) can be assigned to the stretching vibrations of $\mathrm{O}-\mathrm{H}$ and $\mathrm{C}-\mathrm{H}$ stretching of the $-\mathrm{CH}_{2}$ groups at about $3400 \mathrm{~cm}^{-1}$ and $2920 \mathrm{~cm}^{-1}$, respectively. The region from 1200 to $1650 \mathrm{~cm}^{-1}$ corresponds to the typical vibration modes of CMC associated with vibrations relating to the degree of order that is observed for typical cellulosic materials. A peak at $1430 \mathrm{~cm}^{-1}$ could be attributed to a reduced resonance of methylated residues from $\mathrm{CMC}$ after $\mathrm{NC}$ addition (asymmetric bending vibration of $-\mathrm{CH}_{3}$ ). The band at $1319 \mathrm{~cm}^{-1}$ could be attributed to a more crystalline pattern in the conformation of the oxymethyl groups (bending vibration of $\mathrm{O}-\mathrm{CH}_{2}$ ) from cellulose induced by $\mathrm{NC}$ addition.

TGA and DTGA curves for different films CN/CMC: 0/100, 03/97, 05/95 and 10/90 are shown in Figure 8. The TGA curves show weight decreasing pattern of film due to the thermal degradation and the DTGA curves show the maximum decomposition temperature at each stage of thermal degradation. The CMC and NC/CMC bionanocomposites exhibited three major weight loss regions (Figure 7), a maximum decomposition occurred around 210,315 and $500^{\circ} \mathrm{C}$ for the initial, second and the decomposition processes, respectively. After, the evaporation of moisture, the first major decomposition process at a temperature of $140-275^{\circ} \mathrm{C}$ was due to the evaporation of free hydroxyl groups present in both phases, NC and CMC, with the weight loss of about $19 \mathrm{wt} \%$. The second major degradation occurred at around $280-350^{\circ} \mathrm{C}$, which was due to the thermal degradation of the biopolymer chain. The complex decomposition behaviour of sulfonated NC was studied in literature, and the multiple decomposition steps are thought to correspond to different degradation processes, that is, hydrolysis of the outer sulphated cellulose at a first step and decomposition of amorphous traces, followed by dehydration and depolymerisation [54, 55].

WVP of CMC materials is an important challenge for the use $\mathrm{CMC}$ in new applications. Figure 8 shows the effect of NC content on the WVP of the CMC films.

The values of WVP decreased sharply as the content of NC in the films increased. Indeed, the WVP values of CMC films were 116, 112, 109 and $106\left(10^{-4}\right.$ g/h.m.Pa) for films containing 0, 3, 5 , and $10 \% \mathrm{NC}$, respectively. The low WVP value in the NC/ $\mathrm{CMC}$ films can be explained by the removed zone amorphous during NC production, provoking an increase in the crystallinity and promotes a better dispersion of this nanoparticle in the polymeric matrix, producing a network of hydrogen bridges between the $\mathrm{CMC}$ chains and the NC. This arrangement increase the tortuosity in the $\mathrm{NC} / \mathrm{CMC}$ films, leading to slower

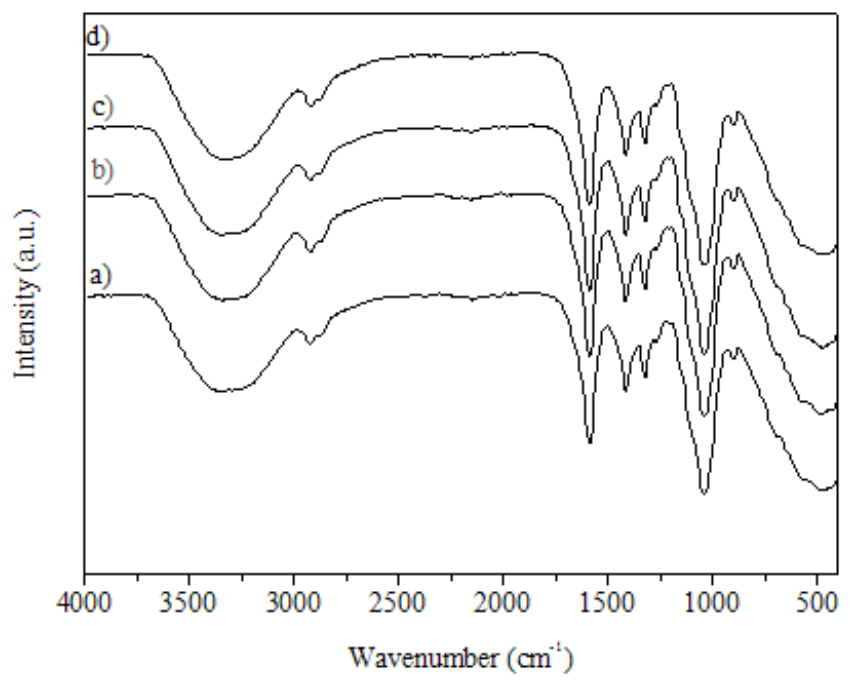

Figure 6: FTIR spectra of a) CMC, b) NC/CMC: 03/97 (w/w), c) NC/ CMC: 05/95 (w/w), and d) NC/CMC: 10/90 (w/w)
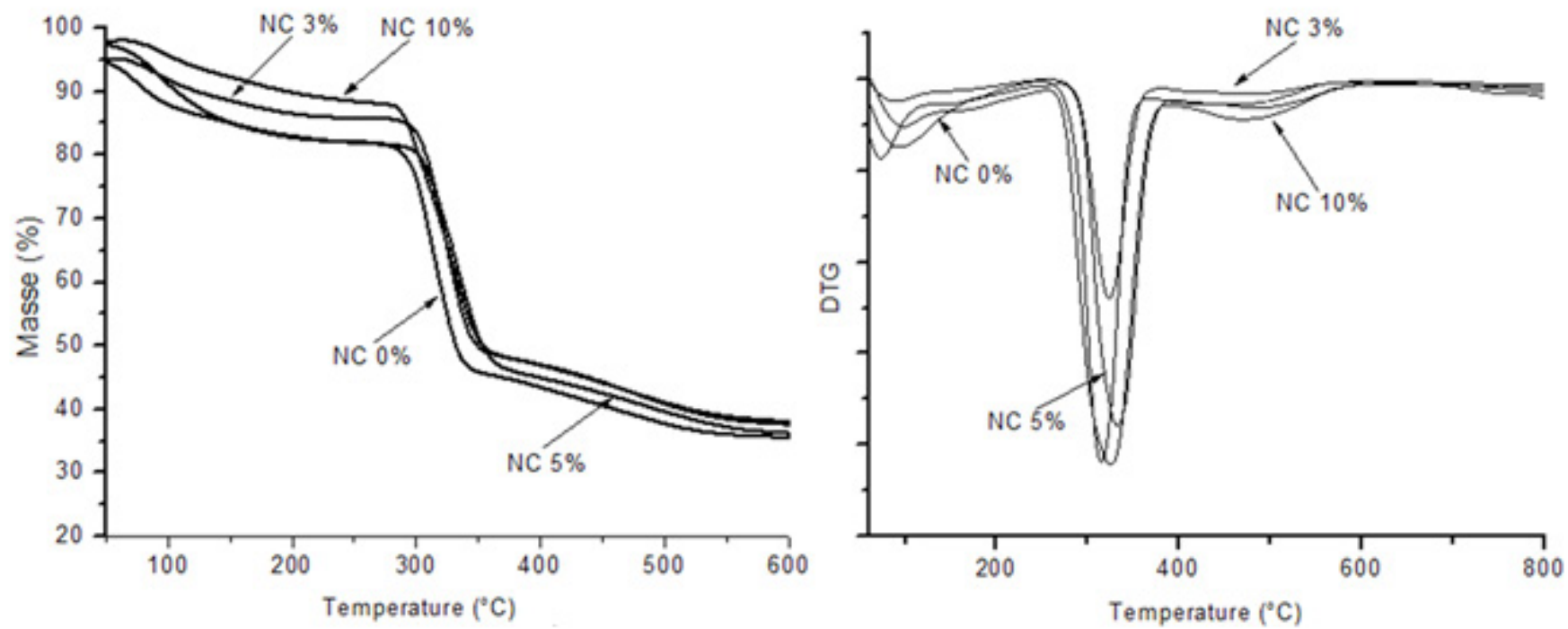

Figure 7: a) TGA and b) DTGA curves of CMC and its bionanocomposite films 
diffusion processes and, hence, to a lower permeability [56]. In addition, the interactions of $\mathrm{NC}$ with $\mathrm{CMC}$ films components as well as the interactions between nanofibres may have enhanced the water vapour barrier [57]. Chang et al. and Azeredo et al. reported that the WVP of starch films [56] and chitosan films [58], respectively, improved significantly by the addition of cellulose nanoparticles.

The mechanical properties, as tensile strength $\left(\sigma_{\mathrm{s}}\right)$, elongation at break $\left(\varepsilon_{b}\right)$ and Young's modulus $(E)$ of neat $C M C$ film and its bionanocomposite films with different filler content of NC were studied by simple tensile test. Figure 9 (a) shows the typical stress-strain curves of the all studied films. From these curves, the mechanical properties are extracted and presented as function of NC percentage.

The CMC films exhibit a Young's modulus of $1.39 \mathrm{GPa}$, an elongation at break of $19.17 \%$ and a tensile strength of 57.2 $\mathrm{MPa}$. For NC/CMC bionanocomposite films, we note after the addition of NC into CMC polymer, an important increase of tensile strength and Young modulus. This could be due to the formation of a network between NC and CMC biopolymer. The network formed generates a strong interaction and hydrogenbonding formation between the hydroxyl and sulphate groups of NC and the CMC polymer. The Young's modulus and tensile strength of the NC/CMC bionanocomposites increased by $60 \%$ from 1.39 to $2.29 \mathrm{GPa}$ and by $47 \%$ from 57.2 to $119.3 \mathrm{MPa}$ when
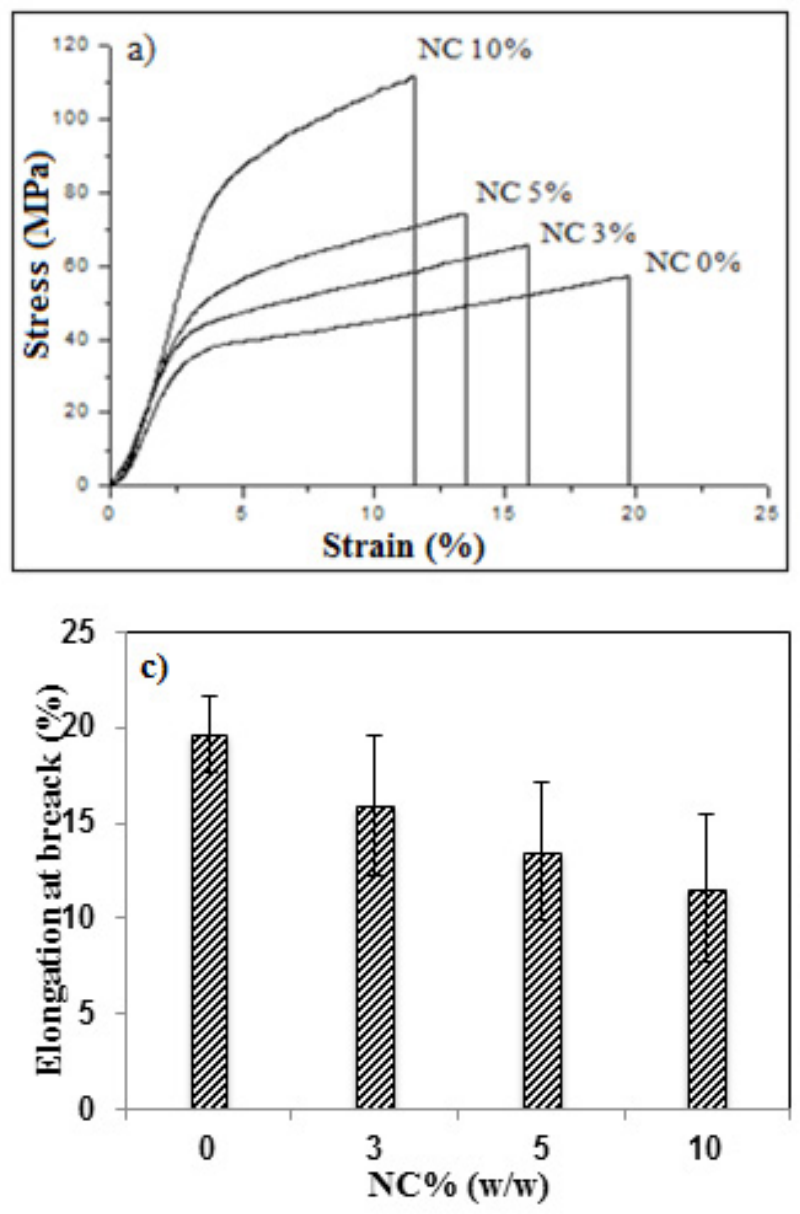

$10 \mathrm{wt} \% \mathrm{NC}$ was added. This results show the improvement of the mechanical properties of the NC/CMC bionanocomposite films compared to the neat $\mathrm{CMC}$. The elongation at break of CMC is affected by the addition of NC, a decrease from $19.7 \%$ for unloaded CMC to $11.6 \%$ when $10 \mathrm{wt} \% \mathrm{NC}$ is added. So the addition of NC improves the rigidity of the biopolymer.

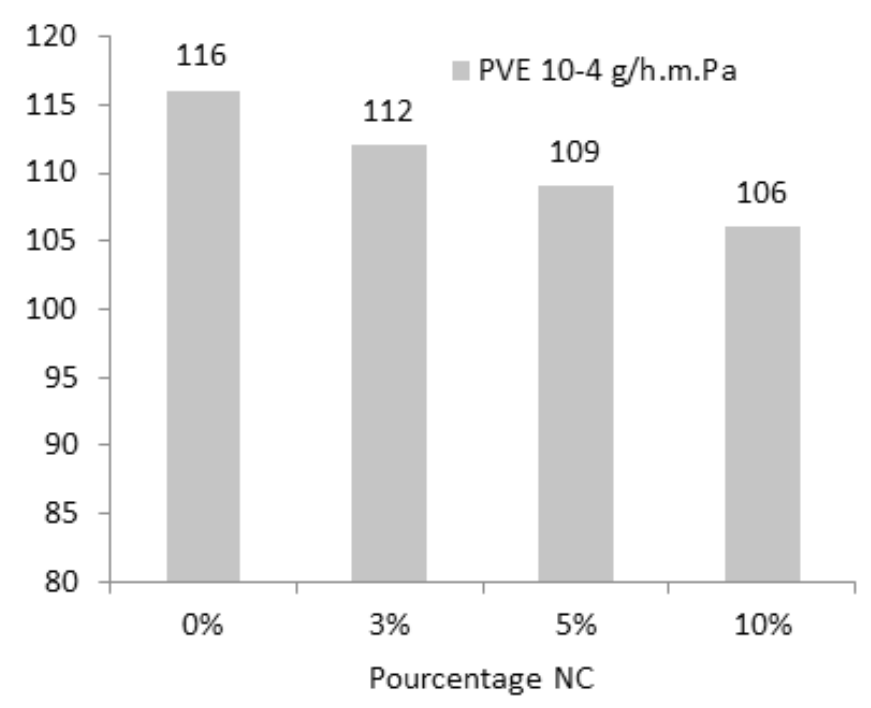

Figure 8: WVP of NC/CMC bionanocomposites
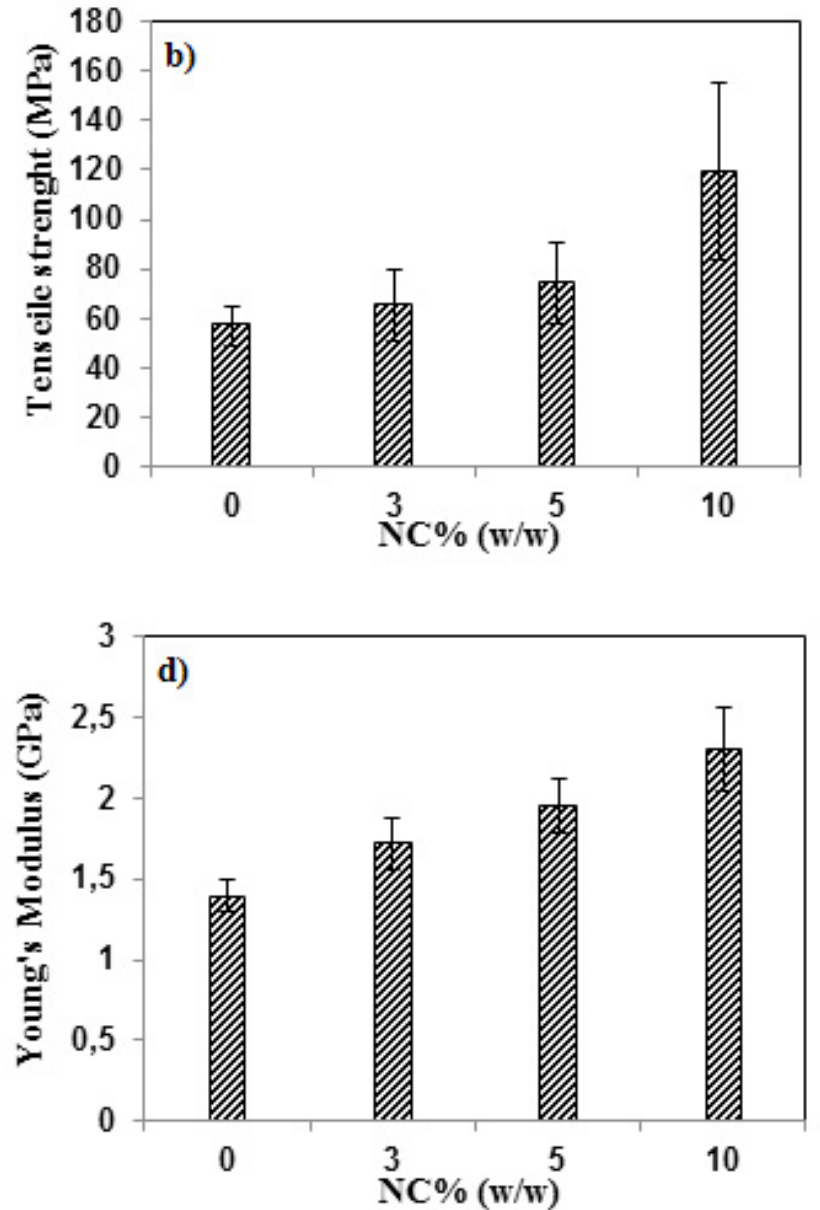

Figure 9: a) Typical stress-strain curves, b) tensile strength, c) elongation at break, and d) Young's modulus of the neat CMC and the bionanocomposite films 
This significant reinforcement impact on the mechanical properties of $\mathrm{CMC}$ polymer can be explained by the large surface area and the very high Young's modulus of NC. In addition, homogeneous dispersion of $\mathrm{NC}$ along with the favourable interfacial interactions between NC and the polymeric matrix are the key points to achieve improvement final tensile properties for the as-prepared bionanocomposite films, resulting in mechanically strong and flexible bio-plastic films.

\section{Conclusion}

NC prepared from Alfa-F, one of the most abundant sources of cellulose in Northern Morocco, has proprieties similar to those of vegetal NC. NC was isolated from Alfa-C fibre using $\mathrm{H}_{2} \mathrm{SO}_{4}$ hydrolysis method and the $\mathrm{NC}$ was used to prepare $\mathrm{NC} / \mathrm{CMC}$ bionanocomposite films with varying concentration of the NC. CN/CMC bionanocomposite films were prepared in water by a casting method. The results revealed that the film properties, such as water vapour barrier and mechanical properties, have significantly improved with lower amount of the NC inclusion. Remarkable increase in tensile properties is clearly visible, especially for the ultimate tensile strength and the Young modulus. These properties can make NC from Alfa-F, a potential material for the preparation of a new class of bionanocomposite films.

\section{References}

[1] Khalil, A., Bhat, H. P. S., IreanaYusra, A. F. (2012). Green composites from sustainable cellulose nanofibrils: A review. Carbohydrate Polymers, 87, 963-979.

[2] Khan, A., Huq, T., Khan, R. A., Riedl, B., Lacroix, M. (2014). Nanocellulose based composites and bioactive agents for food packaging. Critical Reviews in Food Science and Nutrition, 54, 163-174.

[3] Reddy, M. M., Vivekanandhan, S., Misra, M., Bhatia, S. K., Mohanty, A. K. (2013). Biobased plastics and bionanocomposites: Current status and future opportunities. Progress in Polymer Science, 38, 1653-1689.

[4] Sorrentino, A., Gorrasi, G., Vittoria, V. (2007). Potential perspectives of bio-nanocomposites for food packaging applications. Trends in Food Science and Technology, 18, 84-95.

[5] Stevens, C., Verhe, R. (Ed.). (2004). Renewable bioresources - scope and modification for non-food applications. Wiley (New York).

[6] Thomas, S., Pothan, L. (Ed.). (2009). Cellulose fiber reinforced polymer composites. Old City Publishing (Philadelphia)

[7] Belgacem, M.N., Gandini, A. (Ed.). (2008). Monomers polymers and composites from renewable resources. Elsevier (Amsterdam).

[8] Ben Brahim, S., Ben Cheikh, R. (2007). Influence of fiber orientation and volume fraction on the tensile properties of unidirectional Alfa-polyester composite. Composites Science and Technology, 67, 140-147.

[9] Nadji, H., Diouf, P. N., Benaboura, A., Bedard, Y., Riedl, $B$. (2009). Comparative study of lignins isolated from Alfa grass (Stipa tenacissima L.). Bioresource Technology, 100, 3585-3592.

[10] Paiva, M. C., Ammar, I., Campos, A. R., Cheikh, R. B.,
Cunha, A. M. (2007).Alfa fibers: Mechanical, morphological and interfacial characterization. Composites Science and Technology, 67, 1132-1138.

[11] Marrakchi, Z.; Oueslati, H.; Belgacem, M. N.; Mhenni, F.; Mauret E. (2012). Biocomposites based on polycaprolactone reinforced with alfafiber mats. Composites: Part A, 43, 742747.

[12] Nadji, H., Brochier Salon, M. C., Bruzzèse, C., Benaboura, A., Belgacem, M.N. (2006). Chemical composition and pulp properties of Alfa (Stipa tenacissima). Cellulose Chemistry and Technology, 40, 45-52.

[13] Shih, C. M., Shieh, Y. T., Twu, Y. K. (2009). Preparation and characterization of cellulose/chitosan blend films. Carbohydrate Polymers, 78, 169-174.

[14] Erdohan, Z. O., Turhan, K. N. (2005). Barrierand mechanical properties of methyl cellulose-whey protein films. Packaging Technology and Science, 18, 295-302.

[15] Bain, M. K., Bhowmik, M., Ghosh, S. N., Chattopadhyay, $D$. (2009). In situ fast gelling formulation of methyl cellulose for in vitro ophthalmic controlled delivery of ketorolac tromethamine. Journal of Applied Polymer Science, 113, 1241-1246.

[16] Filho, G. R., RosanaAssunc, M. N., Vieira, J. G., Meireles, C., Daniel, A., Cerqueira, D. A., Barud, H. S., Ribeiro, S. J. L., Messaddeq, Y. (2007). Characterization of methylcellulose produced from sugar cane bagasse cellulose: crystallinity and thermal properties. Polymer Degradation and Stability, 92, 205-210.

[17] Heinze, T., Liebert, T., Klüfers, P., Meister, F. (1999). Carboxymethylation of cellulose in unconventional media. Cellulose, 6 (2), 153-165.

[18] Chamsai, B., Sriamornsak, P. (2013). Novel disintegrating microcrystalline cellulose pellets with improved drug dissolution performance. Powder Technology, 233, 278-285.

[19] Kalita, R. D., Nath, Y., Ochubiojo, M. E., Buragohain, A. K. (2013). Extraction and characterization of microcrystalline cellulose from fodder grass; Setariaglauca $(L) P$. Beauv, and its potential as a drug delivery vehicle for isoniazid, a first line antituberculosis drug. Colloids and Surfaces $B$ : Biointerfaces, 108, 85-89.

[20] Levis, S. R., Deasy, P. B. (2001). Pharmaceutical applications of size reduced grades of surfactant coprocessed microcrystalline cellulose. International Journal of Pharmaceutics, 230 (1-2), 25-33.

[21] Oyeniyi, Y. J., Itiola, O. A. (2012). The physicochemical characteristic of microcrystalline cellulose, derived from sawdust, agricultural waste products. International Journal of Pharmacy and Pharmaceutical Sciences, 4, 197-200.

[22] Sanguansri, P., Augustin, M. A. (2006). Nanoscale materials development - A food industry perspective. Trends in Food Science \& Technology, 17(10), 547-556.

[23] Podczeck, F., Al-Muti, E. (2010). The tensile strength of bilayered tablets made from different grades of microcrystalline cellulose. European Journal of Pharmaceutical Sciences, 41, 483-488.

[24] Hanna, M., Biby, G., Miladinove, V. (2001). Production of microcrystalline cellulose by reactive extrusion. US Patent 6,228, 213.

[25] Adel, A. M., Abd El-Wahab, H. Z., Ibrahim, A. A., Al-Shemy, M. T. (2010). Characterization of microcrystalline cellulose prepared from lignocellulosic materials. Part I. Acid catalyzed hydrolysis. Bioresource Technology, 101, 4446-4455.

[26] Janardhnan, S., Sain, M. M. (2006). Isolation of cellulose microfibrils - An enzymatic approach.BioResources, 1(2), 
176-188

[27] Zhang, Y., Liu, Y., Wang, X., Sun, Z., Ma, J., Wu, T., Xing, F., Gao J. (2014). Carbohydrate Polymers, 101, 392-400.

[28] Singh, V., Ahmad, S. (2012). Synthesis and characterization of carboxymethylcellulose-silver nanoparticle (AgNp)-silica hybrid for amylase immobilization.Cellulose, 19 (5), 17591769.

[29] Song, J., Birbach, N. L., Hinestroza, J. P. (2012). Deposition of silver nanoparticles on cellulosic fibers via stabilization of carboxymethyl groups. Cellulose, 19 (2), 411-424.

[30] Chang, P. R., Yu, J., Ma, X., Anderson, D. P. (2011). Polysaccharides as stabilizers for the synthesis of magnetic nanoparticles. Carbohydrate Polymers, 83 (2), 640-644.

[31] Choi, Y., Simonsen, J. (2006). Cellulose nanocrystalfilled carboxymethyl cellulose nanocomposites. Journal of Nanoscience and Nanotechnology, 6 (3), 633-639.

[32] Zakharov, N. A., Ezhova, Z. A., Kalinnikov, V. T., Chalykh, A. E. (2005). Hydroxyapatite-carboxymethyl cellulose nanocomposite biomaterial. Inorganic Materials, 41 (5), 509-515.

[33] Shen, J., Song, Z., Qian, X., Yang, F. (2010). Carboxymethyl cellulose/alum modified precipitated calcium carbonate fillers: Preparation and their use in papermaking. Carbohydrate Polymers, 81(3), 545-553.

[34] Luna-Martinez, J. F., Hernández-Uresti, D. B., ReyesMelo, M. E., Guerrero-Salazar, C. A., González-González, V. A., Sepulveda-Guzman, S. (2011). Synthesis andoptical characterization of ZnS-sodium carboxymethyl cellulose nanocomposite films. Carbohydrate Polymers, 84 (1), 566570.

[35] Basta, A. H., El-Saied, H. (2008). New approach for utilization of cellulose derivatives metal complexes in preparation of durable and permanent colored papers. Carbohydrate Polymers, 74 (2), 301-308.

[36] Segal, L., Creely, J. J., Martin, A. E., Conrad, C. M. (1959). An empirical methodfor estimating the degree of crystallinity of native cellulose using the $X$-ray diffractometer. Textile Research Journal, 29(10), 786-794.

[37] El Achaby, M., Essamlali, Y., El Miri, N., Snik, A., Abdelouahdi, K., Fihri, A., Zahouily M., Solhy, A. (2014). Graphene oxide reinforced chitosan/polyvinylpyrrolidone polymer bio-nanocomposites. J. Applied Polymer Science, 131, issue 22.

[38] Aila-Suárez, S., Palma-Rodríguez, H. M., RodríguezHernández, A. I., Hernández-Uribe, J. P., Bello-Pérez, L. A., Vargas-Torres A. (2013). Characterization of films made with chayote tuber and potato starches blending with cellulose nanoparticles Carbohydrate polymers 98, 102-7.

[39] Sun, X. F., Xu, F., Sun, R. C., Fowler, P., Baird, M. S. (2005). Characteristics of degraded cellulose obtained from steamexploded wheat straw. Carbohydrate Research, 340, 97106.

[40] Sun, R. C., Sun, X. F., Liu, G. Q., Fowler, P., Tomkinson, J. (2002). Structural and physicochemical characterization of hemicelluloses isolated by alkaline peroxide from barley straw. Polymer International, 51 (2), 117-124.

[41] Xiao, B., Sun, X. F., Sun, R. C. (2001). Chemical structural thermal characterization of alkali-soluble hemicelluloses and lignins, and cellulose from rye and rice straws and maize stems. Polymer Degradation and Stability, 74, 307-319.

[42] Trache, D.; Donnot, A.; Khimeche, K.; Benelmir, R.; Brosse N. (2014).Physico-chemical properties and thermal stability of microcrystallinecellulose isolated from Alfa fibers Carbohydrate Polymers 104, 223-230.
[43] Silvério, H.A. et al. (2013). Extraction and characterization of cellulose nanocrystals from corncob for application as reinforcing agent in nanocomposites. Industrial Crops and Products, 44, 427- 436.

[44] Lu, P., Hsieh, Y.-L. (2010). Preparation and properties of cellulose nanocrystals: Rods, spheres, and network. Carbohydrate Polymers, 82, 329-336.

[45] Abeer, M. A., El-Wahab, Z. H. A., Ibrahim, A. A., Al-Shemy, M. T. (2010). Characterization of microcrystalline cellulose prepared from lignocellulosic materials. Part I. Acid catalyzed hydrolysis. Bioresource Technology, 101, 4446-4455.

[46] Alemdar, A., \&Sain, M. (2008b). Biocomposites from wheat straw nanofibers: Morphology, thermal and mechanical properties. Composites Science and Technology,68, 557565.

[47] Maafi, E. M., Malek, F., Tighzert, L., Dony, P. (2010). Synthesis of polyurethane and characterization of its composites based on alfa cellulose fibers. Journal of Polymer Environment, 18, 638-646.

[48] Kalita, R. D., Nath, Y., Ochubiojo, M. E., Buragohain, A. K. (2013). Extraction and characterization of microcrystalline cellulose from fodder grass; Setariaglauca (L) P. Beauv, and its potential as a drug delivery vehicle for isoniazid, a first line antituberculosis drug. Colloids and Surfaces $B$ : Biointerfaces, 108, 85-89.

[49] Li, R., Fei, J., Cai, Y., Li, Y., Feng, J., Yao, J. (2009). Cellulose whiskers extracted from mulberry: $A$ novel biomass production. Carbohydrate Polymers, 76, 94-99.

[50] Maiti, S., Jayaramudu, J., Das, K., Reddy, S. M., Sadiku, R., Ray, S. S. (2013). Preparation and characterization of nanocellulose with new shape from different precursor. Carbohydrate Polymers, 98, 562-567.

[51] Kim, U. J., Eom, S. H., Wada, M. (2010). Thermal decomposition of native cellulose: Influence on crystallite size. Polymer Degradation and Stability, 95, 778-781.

[52] Poletto, M., Pistor, V., Zeni, M., Zattera, A. J. (2011). Crystalline properties and decomposition kinetics of cellulose fibers in wood pulp obtained by two pulping processes. Polymer Degradation and Stability, 96, 679-685.

[53] Khan, R. A., Salmieri, S., Dussault, D., Uribe-Calderon, J., Kamal, M. R., Safrany, A., Lacroix M. (2010). Journal of Agricultural and Food Chemistry, 58, 7878-7885.

[54] Roman, M., Winter, W. T. (2004). Effect of sulfate groups from sulfuric acid hydrolysis on the thermal degradation behavior of bacterial cellulose. Biomacromolecules, 5, 16711677.

[55] Wang, N., Ding, E., Cheng, R. (2007). Thermal degradation behavior of spherical cellulose nanocrystals with sulphate groups. Polymer, 48, 3486-3493.

[56] De Azeredo, H. M. C. (2009). Nanocomposites for food packaging applications.Food Research International, 42, 1240-1253.

[57] Khana, R. A., Salmieria, S., Dussault, D., J., UribeCalderond,Kamal, M. R., Safrany, A., Lacroixa M. (2010). Production and Properties of Nanocellulose-Reinforced Methylcellulose-Based Biodegradable Films.J. Agric. Food Chem. 58, 7878-7885.

[58] Huqa, T., Salmieria, S., Khana, A., Khana, R. A., Le Tiena, C., Riedlb, B., Fraschinic, C., Bouchardc, J., Uribe-Calderond, J., Kamal, M. R., Lacroixa M. (2012). Nanocrystalline cellulose (NCC) reinforced alginate based biodegradablenanocomposite film. Carbohydrate Polymers 90, 1757- 1763. 